\title{
The contribution of traditional healers' clinics to public health care system in Addis Ababa, Ethiopia: a cross-sectional study
}

Wubet Birhan ${ }^{1}$, Mirutse Giday ${ }^{2}$ and Tilahun Teklehaymanot ${ }^{*}$

\begin{abstract}
Background: Ethiopian people have been using traditional medicine since time immemorial with $80 \%$ of its population dependent on traditional medicines. However, the documentation of traditional healers' clinics contribution to modern public health system in cosmopolitan cities is scanty. Studies conducted so far are limited and focused on the perceptions and practices of modern and traditional health practitioners about traditional medicine. Thus, a cross sectional study was conducted from February to May 2010 to assess the contribution of traditional healers' clinics to public health care system in Addis Ababa.
\end{abstract}

Materials and methods: Ten traditional healers who were willing to participate in the study and 306 patients who were visiting these traditional healers' clinics were interviewed using two types of semi-structured questionnaires. Data were summarized using percentages, tables and bar chart.

Results: The diseases mostly treated by traditional healers were wound, inflammation, herpes zoster, hemorrhoids, fracture, paralysis, back-pain, liver diseases, cancer and eczema. This study showed that traditional healers' clinics considerably contribute to public health care in Addis Ababa. Fifty two percent of patients reported that traditional healers' clinics were their first choice when they faced health problems. The reasons for visiting these clinics were 175 (57.2\%) efficacy, 109 (35.6\%) dissatisfaction with modern medicine, 10 (3.3\%) dissatisfaction with modern medicine and efficacy, $6(2.0 \%)$ cost and 6 (2.0\%) dissatisfaction and cost. Females (55.2\%), young age (20-40 years, 65.0\%), never married (56.9\%), orthodox (73.9\%), Amhara (52.3\%), educational status above grade 12 (34.6\%) and government employees (29.4\%) were frequent visitors. Healers reported that there was no form of cooperation with modern health professionals. The reasons were lack of motivation to collaborate and communicate with modern health service workers. Family based apprenticeship was the sources of knowledge for majority of the healers.

Conclusions: The study conducted showed that for the majority of patients interviewed traditional healers' clinics were one of the options to solve their health problems that indicated the considerable contribution of these clinics to the public health care system in Addis Ababa. Nevertheless, in this study the contribution of traditional healers' clinics to the public health system would have been better shown if individuals who are not users of the traditional healers' clinics were included in the interview. However, the study might be useful as a base line data for future evaluation of the significance of traditional healers' clinics for public health system and the services rendered in these clinics.

Keywords: medicinal plant, traditional healers, public health, Addis Ababa, Ethiopia

\footnotetext{
* Correspondence: tilahunmt@yahoo.com

${ }^{2}$ Aklilu Lemma Institute of Pathobiology, College of Health Sciences, Addis

Ababa University, P. O. Box 1176, Addis Ababa Ethiopia

Full list of author information is available at the end of the article
} 


\section{Background}

Traditional medicine refers to health practices, approaches, knowledge and beliefs incorporating plant, animal and mineral-based medicines, spiritual therapies, manual techniques and exercises, applied singularly or in combination to treat, diagnose and prevent illnesses or maintain well-being [1]. Traditional medicine is commonly used to treat or prevent diseases including chronic illness therefore improving the quality of life. It occupies an important place in the health care systems of developing countries. It is estimated that more than $80 \%$ of health care needs in these countries are met through traditional health care practices $[2,3]$.

A traditional healer is defined as an educated or layperson who claims ability or a healing power to cure ailments. He could have a particular skill to treat specific types of complaints or afflictions and might have gained a reputation in her/his own community or elsewhere. Traditional healer may base his power or practice on religion, the supernatural, experience, apprenticeship or family heritage [3-6].

In the last decade, there has been a global increase in the use of traditional and complementary/alternative medicines in both developed and developing countries [5]. The reasons in developing countries are cultural acceptability, perceived efficacy, affordability, accessibility and psychological comfort. The other factors are inaccessibility of modern health services in terms of geography, cost or time, shortage of well-trained modern health professionals [3,6-10].

Eighty percent of human and $90 \%$ of livestock in Ethiopia depend on traditional medicine for primary health care services where modern public health services are limited or note available [3,8-10]. Traditional healers play an essential role in the delivery of primary health care to local people as they treat people in resource poor settings. These people have poor access to modern health services and could not afford the cost for modern health services [3,6,9-11]. However, the contribution of traditional clinics to public health care system in Addis Ababa and other cosmopolitan cities where modern health services are found aggregated is not well documented and studies conducted so far are limited on the perceptions and practices of modern and traditional health practitioners about traditional medicine [6,12-16]. Therefore, the purpose of this study is to document the type of diseases treated by traditional healers, reasons for choosing traditional healers' clinics and magnitude of contribution of traditional healers to public health care system in Addis Ababa. The study might be useful as base line data for future evaluation of the significance of traditional healers' clinics for public health system and the services rendered in these clinics.

\section{Materials and methods \\ Description of the study area}

Addis Ababa is the capital city of Ethiopia with a population of 2.74 million [17]. Its area is estimated to be $530 \mathrm{Km}^{2}$ with altitudes ranging from 2200 to $3000 \mathrm{~m}$ above sea level, average temperature of $22.8^{\circ} \mathrm{C}$ and average rainfall of $1,180.4 \mathrm{~mm}$. Addis Ababa has 30 hospitals, 29 health centers, 122 health stations, 37 health posts and 382 modern private clinics [18].

\section{Study subjects}

Study subjects were 10 traditional healers who were willing to participate in the study, patients, 306, who were willing and attending traditional healers' clinics during data collection period in Addis Ababa.

\section{Ethnobotanical data collections}

The ethnobotanical data were collected using two types of semi-structured questionnaires from February to May 2010: one for traditional healers' clinics clients and the other for traditional healers. Face to face, interviews were conducted with traditional healers and their clients, and individuals accompanying children less than five years. Information on demographic characteristics, use and types of traditional medicine, sources of healing knowledge, number of visitors per day, reasons for visiting traditional healers' clinics, and the common types of diseases treated by healers was collected. The semi-structured questionnaires were prepared in English and discussion with respondents was conducted in the local language, Amharic.

\section{Data analysis}

Data were summarized using percentages and bar chart. Pearson's Chi-squares test was used to show presence or absence of association among different socio-demographic variables with traditional medicine use. P-value of less than 0.05 was considered as statistically significant difference. Single sample $t$ test was conducted to determine variability within each category. SPSS version 13.0-computer software was used to analyze the data.

\section{Ethical clearance}

The study was ethically approved by Institute Review Board of Aklilu Lemma Institute of Pathobiology, College of Health Sciences, Addis Ababa University. Prior to the initiation of the interview, the aim of the study was elaborated to the participants, verbal consents were obtained from both traditional healers, and their clients' that participated in the study. 


\section{Results}

Socio-demographic characteristics of patients visiting traditional healers' clinics

Three hundred and six patients: $44.8 \%$ (137) male and $55.2 \%$ (169) female with a mean age of 28.1 years were interviewed and there was no significant difference between sexes $(p>0.05)$. The participants, young (20-40 years, $65.0 \%)$, never married (56.9\%), orthodox (73.9\%) and Amhara (52.3\%) were frequent visitors of healers' clinics (single sample $t$ test, $\mathrm{p}<0.05$ ) (Table 1 ). There was significant difference within each demographic category (Chi square test, $\mathrm{p}<0.05$ ).

\section{Health seeking behavior of patients visiting traditional healers' clinics}

Traditional healers' clinics were first choice for 172 (56.2\%) patients for diseases like swelling, herpes zoster, wound, fracture, hemorrhoids, paralysis, back-pain, liver diseases, cancer and eczema (Figure 1). One hundred nineteen $(38.9 \%)$ patients got information about traditional healers clinics from friends, 80(26.1\%) from family, 61(19.9\%) from previously treated individuals and $46(15.0 \%)$ form multiple sources. Most patients, 183 (59.8\%) visited traditional healers' clinics escorted by their family, whereas $96(31.4 \%)$ went by themselves, and $27(8.8 \%)$ with friends. One hundred seventy and three (56.5\%) patients visited healers' clinics once, $85(27.8 \%)$ two times, 34(11.1\%) three times, $9(2.9 \%)$ four times and $5(1.6 \%)$ more than 4 times in their life time.

\section{Reasons of visiting traditional healers' clinics}

Seventy-four (24.2\%) patients that visited traditional healers' clinics reported that they were previously treated and cured. They were treated of diseases such as herpes zoster 35(11.4\%), wound 22(7.2\%), eczema 11(3.6\%) and swelling six (2.0\%). The reasons for visiting traditional healers' clinics by patients were 175(57.2\%) efficacy, 109 (35.6\%) dissatisfaction with modern medicine, 10(3.3\%) dissatisfaction with modern medicine and efficacy, 6 (2.0\%) cost and 6(2.0\%) dissatisfaction and cost.

\section{Attitude of patients to traditional healers' clinics}

The majority $(65.4 \%)$ of the patients had positive attitude to the efficacy of traditional medicine and out of these patients, $116(37.9 \%)$ rated the efficacy of traditional healers' service as good and 177 (57.8\%) indicated side effect was low. About Fifty-nine percent of patients reported that they were satisfied with traditional healers' clinics services (single sample $t$ test, $\mathrm{p}<0.05$ ) (Table 2).

\section{Socio demographic characteristics of traditional healers}

The interviewed healers were males with a mean age of 51 years, and had religious education. They started traditional healing practice at their young age (20-40 years) and were generalists that were treating different types of diseases. The majority (70\%) of healers were Orthodox Christians. Their sources of knowledge (50\%) were apprenticeships to parents (Table 3).

\section{Knowledge and Practice of healers in Addis Ababa}

The majority (70.0\%) of healers identified diseases and causes of illness by history-taking and physical diagnosis. During history taking, patient or person accompanying the patient was interviewed about the sign and symptoms of disease, the duration of the disease, age of the patient and history of similar disease in the family. In examination, they observed signs of diseases such as face color, abdomen size and discomfort, wound size and site, and urine color. On the other hand, a minority $(30.0 \%)$ of the healers were using combination of history-taking, physical diagnosis and divination in identifying diseases and determining the type of medication.

\section{Source of medicine, preparation, prescription and fee}

The sources of medicine for the majority of interviewed traditional healers were plants, animals and minerals while for two healers were plants and animals, and for one healer were only plants. Two of the healers had home-gardens for cultivation and as source for some medicinal plants. All healers used both dry and fresh plants parts for preparation of remedies. Crushing, powdering and pounding were indicated by six of the healers as the methods of preparations of herbal drugs, while four of the healers only used squeezing. All healers stored medicinal plants in the form of powder or dried and cut into pieces within a closed container. The time of storage varied among the healers and depended on the type of traditional medicine. The doses of the medicine were measured using cup, spoon, glass, pinch, and lid of the container; it was determined by age of the patient, physical status of the patient, severity of the disease and the experience of individual healer.

All healers had offices for their healing practice but none of them admitted and treated inpatients. Seven (70\%) healers responded that they had additional persons working with them as assistant healers, their number ranged from 1 to 5 . Healers received payment for their services that included registration fee and cost of medicine. The registration fee ranged from 2.00 birr to 20.00 birr (1 ETB $=0.04$ EURO, 0.06 USD) though none of the traditional healers' have formal registration system for their patients. The cost of medicine was paid immediately after getting the treatment and showed variation from healer to healer as well on type of disease 
Table 1 Socio-demographic variables of patients visited traditional healers' clinics in Addis Ababa, 2010

\begin{tabular}{|c|c|c|c|c|c|c|}
\hline \multirow[t]{2}{*}{ Variables } & \multirow[t]{2}{*}{ Number (\%) } & \multicolumn{3}{|c|}{ One-Sample Test } & \multicolumn{2}{|c|}{$95 \%$ Confidence Interval of the Difference } \\
\hline & & $\mathrm{t}$ & d.f. & Sig. (2-tailed) & Lower & Upper \\
\hline Age in years & & 1.699 & 5 & 0.150 & -26.175 & 128.175 \\
\hline $0-4$ & $16(5.2)$ & & & & & \\
\hline $5-9$ & 18(5.9) & & & & & \\
\hline $10-19$ & $26(8.5)$ & & & & & \\
\hline $20-40$ & 199(65.0) & & & & & \\
\hline $41-65$ & $42(13.7)$ & & & & & \\
\hline$>65$ & $5(1.6)$ & & & & & \\
\hline Marital status & & 1.993 & 2 & 0.184 & -118.193 & 322.193 \\
\hline Never married & 174(56.9) & & & & & \\
\hline Married & $129(42.2)$ & & & & & \\
\hline Divorced & $3(1.0)$ & & & & & \\
\hline Religion & & 1.638 & 2 & 0.243 & -165.919 & 369.919 \\
\hline Orthodox & 226(73.9) & & & & & \\
\hline Muslim & $50(16.3)$ & & & & & \\
\hline Protestant & $30(9.8)$ & & & & & \\
\hline Ethnicity & & 1.926 & 7 & 0.095 & -8.709 & 85.209 \\
\hline Oromo & $87(28.4)$ & & & & & \\
\hline Amhara & $160(52.3)$ & & & & & \\
\hline Tigray & $12(3.9)$ & & & & & \\
\hline Wolayita & $8(2.6)$ & & & & & \\
\hline Guragie & $13(4.2)$ & & & & & \\
\hline Silte & $12(3.9)$ & & & & & \\
\hline Hdya & $6(2.0)$ & & & & & \\
\hline Others & $8(2.6)$ & & & & & \\
\hline Educational status & & 3.660 & 4 & 0.022 & 14.828 & 107.972 \\
\hline Illiterate & $30(9.8)$ & & & & & \\
\hline Adult education & $18(5.9)$ & & & & & \\
\hline $1-6$ grade & 64(20.9) & & & & & \\
\hline $7-12$ grade & $89(29.1)$ & & & & & \\
\hline$>12$ grade & 106(34.6) & & & & & \\
\hline Occupation & & 5.023 & 7 & 0.002 & 20.243 & 56.257 \\
\hline Business & $38(12.4)$ & & & & & \\
\hline Daily laborer & $31(10.1)$ & & & & & \\
\hline Farmer & $11(3.6)$ & & & & & \\
\hline Government employee & $78(25.5)$ & & & & & \\
\hline House wife & $31(10.1)$ & & & & & \\
\hline Jobless & $16(5.2)$ & & & & & \\
\hline Private institution & $47(15.4)$ & & & & & \\
\hline Student & $54(17.6)$ & & & & & \\
\hline House hold income & & 8.386 & 3 & 0.004 & 41.574 & 92.426 \\
\hline$<500$ & $65(21.2)$ & & & & & \\
\hline $500-850$ & $59(19.3)$ & & & & & \\
\hline $851-1500$ & $90(29.4)$ & & & & & \\
\hline$>1500$ & $54(17.6)$ & & & & & \\
\hline
\end{tabular}

\section{Referral, collaboration and feed back}

One of the healers responded that he had referred patients to modern health institution and to 'spiritual wholly water' treatment when the illness of the patient was beyond his professional capacity and skill. All interviewed healers did not get help from modern health professionals and did not initiate cooperation with modern health professionals. The reasons mentioned were lack of motivation to collaborate and communicate with modern health service workers and vice versa. The 


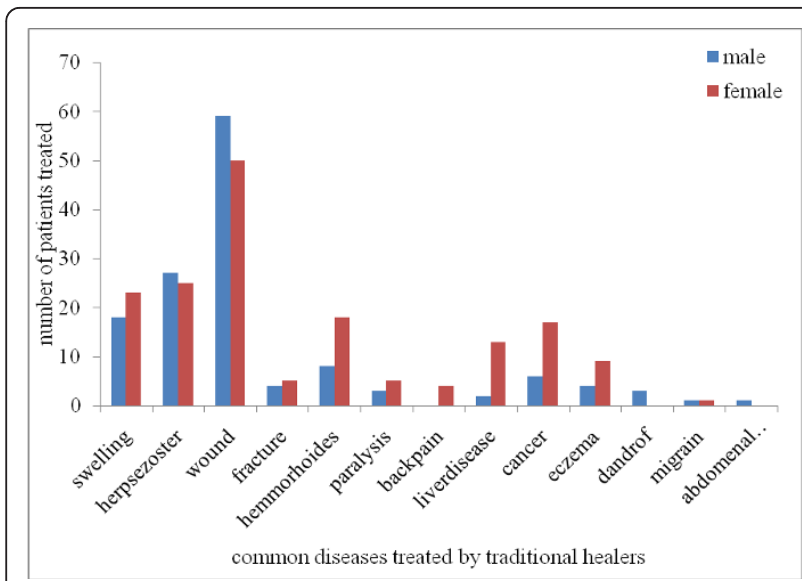

Figure 1 Diseases frequently treated by traditional healers in Addis Ababa, 2010

majority $(60.0 \%)$ of the healers got feedback from their customers on areas such as the strength of their service, efficacy, fees of treatment and medicine.

\section{Discussion}

The number of individuals found in the traditional healers' clinics during data collection period and who responded those traditional healers' clinics as their first choices could indicate the contribution of traditional healers' clinics to the public health system. The number of repeated visits of these clinics by patients and number of individuals that gave information to the patients about traditional healers' clinics that might have previously visited traditional healers' clinics also demonstrated the significance of the traditional healers' clinics for the public health system in Addis Ababa. These showed that a considerable number of the population was treated by the traditional healers' clinics and hence, the contribution of these clinics to public health systems in Addis Ababa.

The majority of patients in this study preferred traditional health care clinics than modern health facilities. Females, individuals with middle-income level and those with education visited traditional healers' clinics more frequently than the rest of informants. This is in agreement with the study done in Trinidad [19]. However, it is different from the studies conducted in California [20], Israel [21] and Colombia University [22] where females, those with higher education and high-income level had statistically significant association with traditional medicine use. In most studies, low income has been mentioned as the reason to visit traditional healers' clinics [9-11] whereas in this study it was not found as a determinant in visiting traditional healers' clinics since other categories were equally important, which was indicated by single sample $t$ test distribution (Table 2).

Reasons indicated by patients that participated in the present study for using traditional medicine as their first choice when they were ill is similar to the study done in Trinidad [19] where efficacy of traditional medicine was the reason for choosing herbal medicine as the first line of health care option. This high efficacy perception may be because traditional medicine was embedded in the belief and culture of the society [9-11]. On the other hand, the study conducted in Addis Ababa to determine the epidemiology of herbal drug use [13] showed that

Table 2 Attitude of patients visited traditional healers' clinics towards traditional healers' clinics in Addis Ababa, 2010

\begin{tabular}{|c|c|c|c|c|c|c|}
\hline \multirow[t]{2}{*}{ Variables } & \multirow[t]{2}{*}{ Number (\%) } & \multicolumn{3}{|c|}{ One-Sample Test } & \multicolumn{2}{|c|}{$95 \%$ Confidence Interval of the Difference } \\
\hline & & $\mathbf{t}$ & d.f. & Sig. (2-tailed) & Lower & Upper \\
\hline Efficacy of traditional medicine(TM) & & 4.31 & 3.00 & 0.02 & 20.02 & 132.98 \\
\hline Very good & $84(27.5)$ & & & & & \\
\hline Good & 116(37.9) & & & & & \\
\hline Fair & $30(9.8)$ & & & & & \\
\hline Difficult to decided & $76(24.8)$ & & & & & \\
\hline Side effect of TM & & 1.30 & 2.00 & 0.32 & -161.72 & 301.06 \\
\hline No & $177(57.8)$ & & & & & \\
\hline Dose & $22(7.2)$ & & & & & \\
\hline It is not known & $107(35.0)$ & & & & & \\
\hline Advise to visit TM & & 2.77 & 2.00 & 0.11 & -56.58 & 260.58 \\
\hline Yes & $172(56.2)$ & & & & & \\
\hline No & $47(15.4)$ & & & & & \\
\hline Difficult to decide & $87(28.4)$ & & & & & \\
\hline Satisfaction & & 2.48 & 2.00 & 0.13 & -75.21 & 279.21 \\
\hline Yes & $182(59.5)$ & & & & & \\
\hline No & $45(14.7)$ & & & & & \\
\hline Difficult to decide & $79(25.8)$ & & & & & \\
\hline
\end{tabular}


Table 3 Socio demographic data on traditional healers in Addis Ababa, 2010

\begin{tabular}{ll}
\hline Socio demographic data & Number (\%) \\
\hline Age in years & \\
$20-40$ & $3(30.0)$ \\
$41-65$ & $6(40.0)$ \\
$>65$ & $1(10.0)$ \\
Marital status & \\
Single & $5(50)$ \\
Married & $5(50)$ \\
Educational status & \\
Religious education & $4(40.0)$ \\
Religious education and grade 1-6 & $3(30.0)$ \\
Religious education and grade 7-12 & $3(30.0)$ \\
Types of practice conducted & \\
Herbalist & $3(30.0)$ \\
Herbalist and bonesetter & $7(70.0)$ \\
Source of traditional healing practice & \\
Apprentice hood to parents & $5(50.0)$ \\
Family, apprentice hood with other person & $4(40.0)$ \\
God gift, apprentice hood with other person & $1(10.0)$ \\
Job other than TM & \\
Yes & $6(60.0)$ \\
No & $4(40.0)$ \\
Do you had work before TM & \\
Yes & $7(70.0)$ \\
No & $3(30.0)$ \\
\hline
\end{tabular}

the main reasons given for choosing herbal medicine as the first line medication option were dissatisfaction with the services of modern health institutions due to their time-consuming practice, cost and perceived efficacy. Study conducted in Nigeria [23] also agrees with the present study that high efficacy of traditional medicine and dissatisfaction with modern medicine were the reasons to visit traditional healers' clinics.

The study conducted in the United States [24] to investigate possible predictors of alternative health care use indicated that those with higher education and poorer health status were associated with alternative medicine use. This is not in agreement with the current study, however level of education had a contribution in visiting traditional healers' clinics.

A majority of patients, in this study, visiting traditional healers' clinics were associated with dermatological cases. Study conducted in Pakistan [25] showed that $43 \%$ of the patients preferred traditional healers for skin disorder treatment indicating that the effectiveness of the remedies given by traditional healers against dermatological diseases.

The finding of this study that majority of patients were satisfied after being treated by traditional healers is corroborated by the study conducted in Zambia [26] and Tanzania [27]. The study conducted in Nigeria [23] indicated that $33.4 \%$ of the respondents reported that herbal medicines had no adverse effects though lower than the current study. The difference could be due to the variation in the dosage and the type of herbs used.

The source of the healers' knowledge in this study is similar to the study conducted in Tanzania [27] where for $41.9 \%$ of the healers were their families. On the other hand most healers in Tanzania kept patient records containing demographic, diagnosis and treatment data whereas in the current study none of the healers kept patient records. The healers in the current study followed traditional treatment systems. Healers in Tanzania [27] agree in diagnosis of patients with this study though they also use laboratory test results made in the hospital in addition to history taking, physical diagnosis, and divination to identify diseases.

In the current study, only one healer referred his patients to modern medicine but the study done in Tanzania (27) showed that almost all healers referred their patients to hospitals when they failed with their own treatment. This difference may be because absence of collaboration and lack of training of traditional healers in Addis Ababa.

\section{Conclusion}

The study conducted showed that for the majority of patients interviewed traditional healers' clinics were one of the options to solve their health problems, which indicated the considerable contribution of these clinics to the public health care system in Addis Ababa. The main reasons for choosing traditional healers' clinics were efficacy, safety of the traditional medicines and affordability of the services provided by the healers' clinics. Nevertheless, in this study the contribution of traditional healers' clinics to the public health system would have been better shown if individuals who are not customers of the healers' clinics were included in the interview. However, the study might be useful as a base line data for future evaluation of the significance of traditional healers' clinics for public health system and the services rendered in the healers' clinics.

\section{Acknowledgements}

We are very much grateful to traditional healers and their clients, who willing fully participated in the study, without whose assistance this study would have been impossible. We thank Addis Ababa University for financial support to conduct the study.

\section{Author details}

${ }^{1}$ College of Medicine and Health Sciences, University of Gondar P. O. BOX 196, Gondar, Ethiopia. ${ }^{2}$ Aklilu Lemma Institute of Pathobiology, College of Health Sciences, Addis Ababa University, P. O. Box 1176, Addis Ababa Ethiopia.

\section{Authors' contributions}

The authors have made substantive intellectual contributions to this study in data collection, identification of plants, preparation of the manuscript and all authors have read and approved the final manuscript. 


\section{Competing interests}

The authors declare that they have no competing interests.

Received: 17 July 2011 Accepted: 2 December 2011

Published: 2 December 2011

\section{References}

1. Traditional medicine promotion efforts. World Health Organization Tech monitor. Geneva 2006.

2. Tabuti JRS, Dhillion SS, Lye KA: Traditional medicine in Bulamogi County, Uganda: its practitioners, users and viability. Journal of Ethnopharmacology 85:119-129.

3. Mussema Y: A historical overview of traditional medicine practices and policy in Ethiopia. Ethiop J Health Dev 2006, 20(2):127-134.

4. Ahmed M, Breme JJ, Magzoub MME, Nouri AMH: Characteristics of visitors to traditional healers in central Sudan. Eastern Mediterranean Health Journal 1999, 5(1):79-85.

5. Teshome-Bahire W: Initiation of Healers in Ethiopia: A Case Study. Coll Antropol 2000, 24(2):555-563.

6. Reniers G, Tesfa R: Health services utilization during terminal illness in Addis Ababa. Ethiopia Health Policy and Planning 24:312-319.

7. National policy on traditional medicine and regulation of herbal medicines: Report of a WHO global survey. Switzerland 2005.

8. Gedif $\mathrm{T}$, Hahn HJ: The use of medicinal plants in self-care in rural central Ethiopia. Journal of Ethnopharmacology 2003, 87:155-161.

9. Giday M, Teklehaymanot T, Animut A, Mekonnen Y: Medicinal plants of the Shinasha, Agew-awi and Amhara peoples in northwest Ethiopia. Journal of Ethnopharmacology 2007, 110:516-525.

10. Yineger $H$, Yewhalaw D: Traditional medicinal plant knowledge and use by local healers in Sekoru District, Jimma Zone, Southwestern Ethiopia. Journal of Ethnobiology and Ethnomedicine 2007, 3(24):3-24.

11. Teklehaymanot T, Giday M: Quantitative ethnobotany of medicinal plants used by Kara and Kwego semi-pastoralist people in lower Omo River Valley, Debub Omo Zone, Southern Nations, Nationalities and Peoples Regional State, Ethiopia. Journal of Ethnopharmacology 2010, 130:76-84.

12. Addis $G$, Abebe $D$, Genebo T, Urga K: Perceptions and practices of modern and traditional health practitioners about traditional medicine in Skirka District, Arisi Zone Ethiopia. Ethiop J Health Dev 2002, 16(1):19-29.

13. Gedif $\mathrm{T}$, Hahn HJ: Epidemiology of herbal drugs use in Addis Ababa, Ethiopia. Pharmacoepidemiology and drug safety 2002, 11:587-591.

14. Gedif T, Hahn HJ: Herbalists in Addis Ababa and Butajira, central Ethiopia: Mode of service delivery and traditional pharmaceutical practice. Ethiopian Journal of Health Development 2002, 16(2):191-197.

15. Teshome-Bahiru W: Impacts of Urbanisation on the Traditional Medicine of Ethiopia. Anthropologist 2005, 8(1):43-52.

16. Ragunathan M, Tadesse H, Tujuba R: A cross-sectional study on the perceptions and practices of modern and traditional health practitioners about traditional medicine in Dembia district, north western Ethiopia. Pharmacogn Mag 2010, 6(21):19-25.

17. Summary and statistical report of the 2007 population and Housing census: Federal democratic republic of Ethiopia population census. CSA, Addis Ababa 2008

18. Wamai RG: Reviewing Ethiopia's Health System Development. International Medical Community JMAJ 2009, 52(4):279-286.

19. Clement YN, Morton GJ, Basdeo L, Blades A, Francis M, Gomes N, Janjua M, Singh A: Perceived efficacy of herbal remedies by users accessing primary healthcare in Trinidad. BMC Complementary and Alternative Medicine 2007, 7:4.

20. Leung JM, Dzankic S, Manku K, Yuan S: The Prevalence and Predictors of the use of Alternative Medicine in Presurgical Patients in Five California Hospitals. Anesth Analg 2001, 93:1062-8.

21. Arye EB, Karkabi K, Karkabi S, Keshet Y, Haddad M, Frenkel M: Attitudes of Arab and Jewish patients toward integration of complementary medicine in primary care clinics in Israel: A cross-cultural study. Social Science and Medicine 2009, 68:177-182.

22. Chao MT, Wade CM: Socioeconomic factors and women's use of complementary and alternative medicine in four racial/ethnic groups. Ethnicity and disease 2008, 18:65-71.
23. Fakeye TO, Adisa R, Musa IE: Attitude and use of herbal medicines among pregnant women in Nigeria. BMC Complementary and Alternative Medicine 2009, 9:53.

24. Astin JA: Why Patients Use Alternative Medicine: Results of a National Study. Journal of American Medical Associations 1998, 279(19):1548-155.

25. Hussain F, Arif M, Ahmad M: Skin Care Knowledge, Attitude and Practices among Pakistani Diabetic Patients. Egyptian Dermatology 2010, 6(1):5.

26. Stekelenburg J, Jager BE, Kolk PR, Westen EH, Kwaak A, Wolffers IN: Health Care seeking behavior and utilization of traditional healers in Kalabo, Zambia. Health Policy 2005, 71:67-81.

27. Gessler MC, Msuya DE, Nkunya MHH, Schair A, Heinrich M, Tanner M: Traditional healers in Tanzania: sociocultural profile and three short portraits. Journal of Ethnopharmacology 1995, 48:145-160.

doi:10.1186/1746-4269-7-39

Cite this article as: Birhan et al:: The contribution of traditional healers' clinics to public health care system in Addis Ababa, Ethiopia: a crosssectional study. Journal of Ethnobiology and Ethnomedicine 2011 7:39.

\section{Submit your next manuscript to BioMed Central and take full advantage of:}

- Convenient online submission

- Thorough peer review

- No space constraints or color figure charges

- Immediate publication on acceptance

- Inclusion in PubMed, CAS, Scopus and Google Scholar

- Research which is freely available for redistribution

Submit your manuscript at www.biomedcentral.com/submit
Ciomed Central 